\title{
Numerical and Experimental Study on Microstructure Evolution of Ti-6Al-4V Alloy Shaft Perform in Cross-Wedge Rolling Process
}

Jiayao Yuan

Ningbo University

Xing Chen ( $\square$ chenxing@nbu.edu.cn )

Ningbo University https://orcid.org/0000-0002-1848-2533

Zhilong Zhao

Ningbo University

Baoshou Sun

Ningbo University

Xuedao Shu

Ningbo University

\section{Original Research}

Keywords: Ti-6Al-4V, alloy shaft preform, cross-wedge rolling, Average grain size, Dynamic recrystallization volume fraction, microstructural evolution

Posted Date: February 11th, 2021

DOl: https://doi.org/10.21203/rs.3.rs-177819/v1

License: (c) (1) This work is licensed under a Creative Commons Attribution 4.0 International License. Read Full License 


\section{Abstract}

To seek a fundamental understanding for further improving the Ti-6Al-4V alloy utilization of Cross-Wedge Rolling (CWR) and the comprehensive mechanical properties of shaft parts, the effect of the CWR processing parameters on the microstructure evolution of Ti-6Al-4V alloy shaft preform is studied in this paper. An Arrhenius-type microstructure structure evolution model was employed and implemented into the finite element software DEFORM-3D. The average grain size and dynamic re-crystallization volume fraction distribution in the $\alpha+\beta$ two-phase region and the $\beta$ single phase region under different rolling temperature, roller rotating speed and area reduction were analyzed, respectively. It is finding that the area reduction, rolling temperature and roller rotating speed significantly affect the microstructure evolution of Ti-6Al-4V alloy. Meanwhile, the corresponding CWR and Metallographic experiments were conducted to verify the reliability of the FE simulation results. Results showed that the agreement of the process parameters effect on dynamic recrystallization in the $\alpha+\beta$ two-phase region between simulation and experimental is reasonably good. The difference in average grain size in the $\beta$ phase region between simulation and experimental is ranged from $5.77 \%$ to $18.56 \%$. In addition, the evenly distributed microstructure can be found as the area reduction of $50 \%$, rolling temperature of $950^{\circ} \mathrm{C}$ and the speed of $5 \mathrm{r} \cdot \mathrm{min}^{-1}$ were employed. After rolling under optimized processing conditions, the tensile strength of Ti$6 \mathrm{Al}-4 \mathrm{~V}$ alloy shaft preform increased by $18.57 \%$ and the plasticity enhanced significantly due to smaller grain size and bi-model microstructure obtained.

\section{Introduction}

Titanium alloy has superior material properties, which has been widely used in aircraft and automobiles to reduce weight and save energy. At the same time, it can also improve the safety of the equipment $[1,2]$. Ti-6Al-4V(TC4) is the most typical representative of two-phase titanium alloy that considered the most widely used titanium alloy at present. In recent years, with the improvement of automobile energy conservation and environmental protection standards, the application of TC4 in automobile has been significantly strengthened and expanded, which shows that TC4 used in automobile is a very attractive potential huge market. Therefore, to achieve better mechanical properties shaft such as drive shafts, piston bolts, drive rods, and support centre rods, TC4 is more and more widely used in axial components [3-5].

It is well known that titanium alloy has a limited forming window due to the lower thermal conductivity. In order to obtain the desirable microstructure with excellent mechanical behaviour, hot forging is a conventional and preferred process to manufacture shaft. However, extrusion and upsetting are often used to perform the shaft prior to forging. The main drawbacks of the conventional process are multiple operations, high production cost and limited tool life [6, 7]. Thus, cross wedge rolling, an innovative nearhet plastic forming process, has been put forward to be a substitute process for manufacturing preform of shaft [8]. Cross wedge rolling is one of the most effective plastic deformation methods that is utilized for the production of shaft parts with refined grains and improved mechanical properties, such as highspeed railway axles and hollow valves [9]. Many investigations have been carried out on the CWR process 
[10-12]. Pater et al. [13-15] researched the modelling method and the experimental rolling of CWR using theoretical and experimental studies. Lovell et al. [16-19] systematically investigated failure conditions and criterion for CWR as well as the reason for slipping, necking, and internal defects in the workpiece during the CWR process. Lee et al. [20] optimized the CWR process based on the response surface methodology to prevent internal hole defects from forming. The above scholars have made great contributions in promoting the field of cross wedge rolling. In the process of lightweight shaft parts, the traditional forming method has many shortcomings. In order to solve this problem, The technique of forming the ideal lightweight material TC4 for shaft parts by cross wedge rolling(CWR) was proposed in this paper.

In recent years, many scholars have done a lot of researches on forming titanium alloy shafts using cross wedge rolling (CWR). Depending on the CWR, the investigations of the titanium alloy generally falls into two categories. The first category mainly focused on the titanium alloy shaft preform forming quality and properties. In this regard, Li et al. [21, 22] investigated the effects of forming angle, stretching angle and area reduction on the formability of TC4 titanium alloy CWR parts. Pater et al. $[23,24]$ researched the formability of TC4 titanium alloy CWR driving shafts on helicopters using numerical simulations after comparing deformation resistance of aluminum alloy, titanium alloy and magnesium alloy during the rolling process. Arkadiusz et al. [25] compared the forming quality of TC4 titanium alloy stepped shafts formed by CWR and forging, and found that the precision of cross wedge rolling was much higher than that of forging. Researches on the macroscopic structure of titanium alloy CWR shafts have also been attempted. Li et al. [26] Investigating the effects of process parameters on the cross wedge rolling of TC6 alloy based on temperature and strain rate sensitivities. Different from the macroscopic structure investigated, Microstructure influences the mechanical properties of alloys, such as strength, ductility, creep resistance, fracture toughness and crack propagation resistance. The control and optimization of microstructure is one of the important issues in the study of TC4 alloy forming during CWR. Ding et al. [27]. In this field, Li et al. [28] investigated the microstructure evolution and mechanical properties of a TC6 alloy blade preform produced by cross wedge rolling. As a dual-phase $(a+\beta)$ titanium [29], the researches on two phase's effect of process parameters on dynamic recrystallization for Ti-6Al-4V are necessary. With more slip systems, the body center cubic (BCC) structure is easier to be formed than the hexagonal close-packed (HCP) structure [30]. Accommodation deformation mainly occurs in $\beta$-phase grain growth extraordinarily easy to occur in $\beta$-phase during cross wedge rolling [31]. The microstructure of TC4 alloy during the CWR process has a significant effect on the mechanical properties of final products. Thus, a better understanding of the influence of TC4 dynamic recrystallization and average grain size during CWR is extremely significant [32-34]. Compared with the macroscopic structure analysis of titanium alloy shafts by cross wedge rolling,few researches were made on the evolution of CWR shafts in microstructure, which has resulted in the limited application of CWR technology in titanium alloy shaft preform forming.

In this paper, the influence rules of the Dynamic recrystallization and average grain size of Ti-6Al-4V alloy during CWR were studied, which will provide a guidance for the application of $\mathrm{Ti}-6 \mathrm{Al}-4 \mathrm{~V}$ alloy to improve the mechanical properties of the shaft parts. The microstructure model of Ti-6 Al- $4 \mathrm{~V}$ alloy was 
employed and implemented into the finite element software DEFORM to study the effects of microstructure evolution under different conditions of CWR. To verify numerical predictions, a comparison of microstructures in average grain size and dynamic recrystallization between simulated and experimental was conducted for $\mathrm{Ti}-6 \mathrm{Al}-4 \mathrm{~V}$ alloy. In addition, the microstructure evolution of $\mathrm{Ti}-$ 6Al-4V alloy shafts during CWR was obtained comprehensively. Furthermore, TC4 alloy shaft preforms were successfully fabricated by CWR based on optimized parameters, which is confirmed experimentally to have the strengthened mechanical properties of the shaft perform produced by CWR.

\section{Fe Simulation Of Cross Wedge Rolling}

\subsection{Constitutive equation and re-crystallization model of material Ti-6Al-4V alloy}

The material used in this work was Ti-6Al-4V alloy, as an ideal lightweight material for shaft parts, whose chemical composition are tabulated in Table 1. The initial microstructure of TC4 alloy is mainly composed of equiaxed a-phase; lamellar a-phase and intergranular $\beta$-phase,as shown in Fig. 1.

Table 1

Chemical element content of Ti-6Al-4V alloy (mass fraction \%)

\begin{tabular}{|llllllll|}
\hline Element & $\mathbf{T i}$ & $\mathbf{A l}$ & $\mathbf{V}$ & $\mathbf{0}$ & $\mathbf{N}$ & $\mathbf{C}$ & $\mathbf{H}$ \\
\hline percentage & 89.221 & 6.4 & 4.2 & 0.15 & 0.01 & 0.01 & 0.01 \\
\hline
\end{tabular}

Under the CWR experimental conditions, the deformation temperature and strain rate have great influence on the rheological stress of Ti-6Al-4V alloy. Typical true stress-strain curves under $a+\beta$ two-phase region $\left(950^{\circ} \mathrm{C}\right)$ and $\beta$ single-phase $\left(1050^{\circ} \mathrm{C}\right)$ region conditions are shown in Fig. 2 . The constitutive model equation of materials is a basic mathematical expression to describe the stress and strain relationship of materials, and the evolution of microstructure [33] of materials as well. The Arrhenius strain equation has been widely used to describe the relationship among flow stress, strain rate and temperature [35]. In this paper, constitutive equations of $\alpha+\beta$ two-phase region and $\beta$ single-phase were employed in according to literatures [33-34]. For $\alpha+\beta$ two region, the material constant $A$ is $e^{17.61}$, the stress index $N$ is 5.18 , and the thermal deformation activation energy $Q$ is $418400 \mathrm{~J} \cdot \mathrm{mol}^{-1}$. In $\beta$ single-phase region, the material constant $A$ is $e^{4.43}$, the stress index $N$ is 6.3 , and the activation energy $Q$ of thermal deformation is $316500 \mathrm{~J} \cdot \mathrm{mol}^{-1}$. The constitutive equation and microstructural evolution model of $\mathrm{Ti}-6 \mathrm{Al}-4 \mathrm{~V}$ alloy in different phase regions are shown in Table 2.

Specially, compared with $\beta$ single-phase alloy with obvious grain boundaries in microstructure, $a+\beta$ twophase has no obvious grain boundaries in microstructure. Therefore, the $\alpha+\beta$ two-phase dynamic recrystallization grain size equation was not explored in this paper.

\subsection{The establishment of finite element model}


The CWR model was established with Cro-E software and then was imported into DEFORM-3D software in STL format. The main calculation parameters of the CWR simulation are presented in Table 3.

To achieve simulation, a DEFORM-3D elastic-plastic FE model was applied under the following assumptions: (1) the tools and guide plates are assumed to be rigid body due to their negligible deformation. The workpiece is considered as a plastic body due to the negligible elastic deformation. (2) Half of the shaft is taken to build the symmetrical shaft; the symmetry constraint is applied to save the computation time. (3) The contact relationship between the rolled piece and the guide plate was neglected. Meanwhile, the friction coefficient between the top and bottom dies and the workpiece was set as constant value of 2 . The billet was divided into tetrahedral elements of 50000 . Figure 3 shows finite element model of cross wedge rolling that includes CWR rolls, guide plates and billets.

To study the influence of the microstructure evolution of Ti-6Al-4V alloy shaft during CWR, the derived material parameters and microstructure model tabulated in Table 2 were imported into DEFORM-3D. Numerical experiments under different process parameters tabulated in Table 4 were carried out. Please be noted that the forming angle and stretching angle, which are not substantial in the phase transformation and temperature distribution, were not considered as a variable in the present work.

Table 3

Main simulation parameters of the CWR

\begin{tabular}{|ll|}
\hline Parameter & Value \\
\hline Forming angle of tools $/\left({ }^{\circ}\right)$ & 24 \\
Stretching angle of tools $/\left(^{\circ}\right)$ & 4 \\
Tools temperature $/\left({ }^{\circ} \mathrm{C}\right)$ & 20 \\
Ambient temperature $/\left({ }^{\circ} \mathrm{C}\right)$ & 20 \\
Friction coefficient & 0.9 \\
Heat transfer coefficient $/\left(\mathrm{N} / \mathrm{s} / \mathrm{mm} /{ }^{\circ} \mathrm{C}\right)$ & 11 \\
Convection coefficient $/\left(\mathrm{N} / \mathrm{s} / \mathrm{mm} /{ }^{\circ} \mathrm{C}\right)$ & 0.02 \\
\hline
\end{tabular}


Table 4

Main process parameters of FE simulation

\begin{tabular}{|llll|}
\hline Serial no. & Rolling temperature $\left({ }^{\circ} \mathrm{C}\right)$ & roller rotating speed $(\mathrm{r} / \mathrm{min})$ & area reduction $(\%)$ \\
\hline 1 & $850,900,950$ & 5 & 50 \\
2 & 950 & $2,5,8$ & 50 \\
3 & 950 & 5 & $30,50,70$ \\
4 & $1000,1050,1100$ & 5 & 50 \\
5 & 1050 & $2,5,8$ & 50 \\
6 & 1050 & 5 & $30,50,70$ \\
\hline
\end{tabular}

\subsection{Simulation results and analysis}

\subsubsection{Microstructure evolution at each stage of CWR}

The dynamic recrystallization volume fraction in different phase region at the wedging, stretching and sizing section during CWR process are shown in Figs. 4, and 5.

When rolling temperature is $950^{\circ} \mathrm{C}, \mathrm{Ti}-6 \mathrm{Al}-4 \mathrm{~V}$ alloy is in the $\alpha+\beta$ two-phase region. During the wedging section of the rolling process, dynamic recrystallization only occurs in the contact area between the rolled workpiece and the cross wedge rolling die, and the volume fraction of dynamic recrystallization gradually decreases from the surface to the inside, while no dynamic recrystallization occurs in the uncontacted area, as shown in Fig. 4a. After entering the stretching section, with the expansion of the deformation area, the area of dynamic recrystallization continues to expand and has penetrated to the core of the rolled piece. At this time, the volume fraction of dynamic recrystallization in the deformation area of the whole billet has reached $100 \%$, but there is still no dynamic recrystallization at the end of the billet, as shown in Fig. 4b. In the sizing section, the process of dynamic recrystallization in the forming area is almost completed, and the volume fraction of dynamic recrystallization in the deformation area has basically reached $100 \%$, the dynamic recrystallization volume fraction at the end of rolled piece still shows a decreasing trend from the surface to the center, as shown in Fig. 4c. It can be observed that completion of the dynamic recrystallization is easier as the contact and deformation are occurred, as shown in Fig. 4a-4c. This is because the contact areas have the largest dislocation density and the maximum distortion energy stored in the deformed alloy. Therefore, there will be more activation energy provided to the recrystallization of the contact and deformed area.

As shown in Fig. 5 , when rolling temperature is $1050^{\circ} \mathrm{C}, \mathrm{Ti}-6 \mathrm{Al}-4 \mathrm{~V}$ alloy is in the $\beta$ single-phase region. Dynamic recrystallization occurs in the contact area and its adjacent area during the wedging section, as shown in Fig. 5a. In the stretching zone, it is observed that the dynamic recrystallization area expands continuously with the increase of the deformation area but the dynamic recrystallization does not occur at the undeformed regional core, as shown in Fig. 5b. After entering the sizing zone, dynamic 
recrystallization occurred almost throughout the rolled parts, as shown in Fig. 5c. Comparing Figs. 4 and 5 , it can be seen that completion of the dynamic recrystallization is easier and is more abundant in $\beta$ single-phase rolling process. The primary cause is that there will be more activation energy provided to the recrystallization when rolling temperature is $1050^{\circ} \mathrm{C}$.

\subsubsection{Effect of rolling temperature}

To more efficiently and completely study the effect of process parameters on the microstructure of $\mathrm{Ti}-$ $6 \mathrm{Al}-4 \mathrm{~V}$ alloy during cross-wedge rolling, the temperature-dependent microstructure evolution model was employed to study the effect of process parameters on dynamic recrystallization in $\alpha+\beta$ two-phase region. However, the influence of process parameters on the average grain size of dynamic recrystallization will be explored in $\beta$ single phase region due to the almost completion of recrystallization in $\beta$ single phase region.

Figure 6 shows the dynamic recrystallization volume fraction effect of Ti-6Al-4V alloy shaft under different rolling temperature for an area reduction of $50 \%$ and roller rotating speed of $5 \mathrm{r} \cdot \mathrm{min}^{-1}$. It is observed that the rolling temperature had a remarkable effect on dynamic recrystallization. When the initial temperature was $850^{\circ} \mathrm{C}$, there was no dynamic recrystallization in the large dark blue area at the end of the rolled workpiece, and the dynamic recrystallization volume fraction was still 0 , as shown in Fig. 6a. When the initial temperature is $900^{\circ} \mathrm{C}$ and $950^{\circ} \mathrm{C}$, the center area at the end of the rolled piece without dynamic recrystallization continues to shrink, as shown in Fig. $6 \mathrm{~b}$ and 6c. Comparing Fig. 6a,6b and $\mathrm{c}$, it is found that dynamic recrystallization is becoming more complete as the rolling temperature is increased from $850^{\circ} \mathrm{C}$ to $950^{\circ} \mathrm{C}$.

Fig 7 shows the distribution of the average grain size of $\mathrm{Ti}-6 \mathrm{Al}-4 \mathrm{~V}$ alloy shaft at different rolling temperature as an area reduction of $50 \%$ and a rolling speed of $5 \mathrm{r} / \mathrm{min}$ are employed. It can be seen that the average grain size distribution of the rolling piece was approximately $156-206 \mu \mathrm{m}$ at $1000^{\circ} \mathrm{C}, 165-227$ $\mu \mathrm{m}$ at $1050^{\circ} \mathrm{C}$, and $226-286 \mu \mathrm{m}$ at $1100^{\circ} \mathrm{C}$, as shown in Fig $7 \mathrm{a}, 7 \mathrm{~b}$ and $7 \mathrm{c}$, respectively. It is clearly shown that grain refinement occurs in the rolling parts after cross wedge rolling at all temperatures. By comparing the grain size at different rolling temperatures, it can be seen that the values of average grain size gradually grow as the rolling temperature increased. This is mainly because high temperatures provide enough driving force and lead to a substantial amount of nucleation and fast growth.

\subsubsection{Effect of the roller rotating speeds}

Figure 8 presents the dynamic recrystallization volume fraction of $\mathrm{Ti}-6 \mathrm{Al}-4 \mathrm{~V}$ alloy shaft under different roller rotating speeds of $2 \mathrm{r} \cdot \mathrm{min}^{-1}, 5 \mathrm{r} \cdot \mathrm{min}^{-1}$ and $8 \mathrm{r} \cdot \mathrm{min}^{-1}$ when an area reduction of $50 \%$ and the rolling temperature of $950^{\circ} \mathrm{C}$ are employed. As the roller speed is changed from $2 \mathrm{r} \cdot \mathrm{min}^{-1}$ to $5 \mathrm{r} \cdot \mathrm{min}^{-1}$, the region of dynamic recrystallization is larger due to competing effect of temperature, as shown in Fig. $8 \mathrm{a}$ and $8 \mathrm{~b}$. However, it is observed that the region of the dynamic recrystallization becomes smaller due to rolling time shortened significantly, so that as shown in Fig .8c. 
The average grain size results of $\mathrm{Ti}-6 \mathrm{Al}-4 \mathrm{~V}$ alloy shaft under different roller rotating speeds are shown in Fig. 9. It is observed that the rolling speed has a great influence on the grain size. At the rolling speed of $2 \mathrm{r} \cdot \mathrm{min}^{-1}$, the grain size of the rolled piece was ranged from $225 \mu \mathrm{m}$ to $275 \mu \mathrm{m}$. The grain size of the rolled piece was ranged from $165 \mu \mathrm{m}$ to $227 \mu \mathrm{m}$ as the rolling speed is $5 \mathrm{r} \cdot \mathrm{min}^{-1}$. The grain size of the rolled piece decreased to $187 \mu \mathrm{m}$ as the rolling speed of $8 \mathrm{r} \cdot \mathrm{min}^{-1}$ was employed. It is found that the faster the rolling speed is, the smaller the grain size is. This is mainly because the rolling time will be shortened as the rolling speed increased and thus the dynamic recrystallization grain nucleation does not have enough time to grow up, as expected.

\subsubsection{Effect of the area reduction rate}

Figure 10 shows the dynamic recrystallization volume fraction of $\mathrm{Ti}-6 \mathrm{Al}-4 \mathrm{~V}$ alloy shaft under different area reduction rate of $30 \%, 50 \%$, and $70 \%$ as the roller rotating speeds of $5 \mathrm{r} \cdot \mathrm{min}^{-1}$ and the rolling temperature of $950^{\circ} \mathrm{C}$ were employed. When the area reduction is $30 \%$, the dynamic recrystallization volume fraction is nearly $0 \%$ at the center of unrolled workpiece end, as shown in Fig. 10a. When the area reduction rate is $50 \%$, it is found that the region without dynamic recrystallization is significantly reduced, as shown in Fig. 10b. When the area reduction is $70 \%$, dynamic recrystallization continues to spread in all areas of the rolled workpiece and the volume fraction of the rolled workpiece increases gradually from the inner area to the surface, as shown in Fig. 10c. It is obvious that the averaged dynamic recrystallization volume fraction in the center of unrolled workpiece end gradually increases as the area reduction rate increased. This is mainly due to that the activated energy provided for dynamic recrystallization will increase as the area reduction rate increases.

Fig. 11 shows the average grain size distributions of rolled workpiece in $\beta$ single-phase region under different area reduction rates of $30 \%, 50 \%$, and $70 \%$. From the results of numerical simulation, it can be seen clearly that the area reduction rate has a significant effect on the grain size. The averaged grain size of rolled piece was ranged from $246 \mu \mathrm{m}$ to $288 \mu \mathrm{m}, 165 \mu \mathrm{m}$ to $227 \mu \mathrm{m}$ and $99.8 \mu \mathrm{m}$ to $182 \mu \mathrm{m}$ when the area reduction was $30 \%, 50 \%$, and d $70 \%$ respectively, as shown in Fig. 11 . By comparing their grain size, it is found that the average grain size decreases with the increase of area reduction rates. This is mainly because the increase of the area reduction will result in the increase of material deformation and making it easier for grains to be broken. Therefore, the dynamic recrystallization energy also increases, which will promote the increase of the numbers of dynamic recrystallization nucleation, and finally lead to more refined grains.

\section{Experimental Verification \\ 3.1 Experiment preparations}

To verify FE simulation results of the CWR process, the corresponding CWR experiments were carried out on the H630 CWR machine at the Zhejiang Provincial Key Lab of Part Rolling Technology, China. The CWR machine (Brand H630, made in Beijing,China) in the laboratory are shown in the left side of Fig. 12. 
Before rolling, The billet should be heated to the temperature range of $850^{\circ} \mathrm{C} \sim 1050^{\circ} \mathrm{C} \square$ and the high temperature furnace was used for heating. After the billet was heated to the set temperature, the heated billet was transferred to the rollers. Then, the rolling experiment was carried out. The Ti-6Al-4V alloy shafts before (red) and after cooling (dark) are enlarged and shown in the right side of Fig. 12 in different color. The comparison of simulated and experimental rolled shape of Ti-6Al-4V alloy shaft is shown in Fig. 13. It is observed that the similar shape results of simulated and experimental rolled part can be obtained.

The primary aim of metallographic experiment was to study the microstructure of the Ti-6Al-4V alloy shaft before and after CWR. Firstly, the specimen was sampled at the specific position of the rolled shaft and then the sample was fabricated by a mosaic machine (type: XQ-1, made in Shanghai, China). Secondly, the sample was grinded by metallographic sanding paper with different grain sizes on metallographic grinding (type: YM-2C, made in China). Thirdly, the grinded sample was polished at the top surface using metallographic polishing machine (type: PG-2A, made in China). For the best observation of the polished surface, the specimen surface was eroded effectively by the etching solution which was mixed by hydrofluoric acid (HF), nitric acid $\left(\mathrm{HNO}_{3}\right)$ and water $\left(\mathrm{H}_{2} \mathrm{O}\right)$ at 1:2:7. Finally, the specimen surface after corrosion was observed using optical metallographic microscope (type: HiROXKH8700 , made in Shanghai, China) and the average size of grain was measured by Nano-measurer software. The flowchart for measuring metallographic microstructure of the Ti-6Al-4V alloy shaft is outlined in Fig. 14. To check microstructures at different positions, the samples are chosen at three different locations of the part for measuring, as shown in Fig. 15.

\subsection{Results and discussion}

\subsubsection{Effect of rolling temperature}

To verify simulation results of the microstructure evolution with the rolling temperature, the metallographic experiment under different rolling temperature for an area reduction rate of $50 \%$ and roller rotating speed of $5 \mathrm{r} / \mathrm{min}$ were conducted and the metallographic images obtained, as shown in Fig. 16. It can be clearly seen that there are a bulk of connected primary a in Fig. 16a as the rolling temperature is $850{ }^{\circ} \mathrm{C}$. As the rolling temperature increases to $900^{\circ} \mathrm{C}$, the primary a is significantly reduced both in shape and contents and equiaxial primary a are occurred, as shown in Fig. 16b. It is mainly because the primary a phase is transformed from the original bulk continuous grain to the independent equiaxed a grain. As the rolling temperature continues to rise at $950{ }^{\circ} \mathrm{C}$, most of the primary a-phases are still equiaxial, but its content is sequentially reduced. Meanwhile, the lamellar a-phases appear, as shown in Fig. 16c. These bimodal microstructures of a phase has the advantages of equiaxed and lamellar microstructure, which has the comprehensive properties of high strength, good plasticity, good toughness and heat stability. This can be a remarkable indicator to measure the quality of a shaft [3]. With the rolling temperature increases to $1000^{\circ} \mathrm{C}$, it can be seen that the content of primary-a phase is minimized and the average grain size of $\beta$ phase gradually increases, as shown in Fig. $16 \mathrm{~d}$. This is because the transition from a phase to $\beta$ phase is further enhanced under the rolling temperature of $1000^{\circ} \mathrm{C}$. 
As shown in Fig. 16e, the comparison of experimental and simulated average grain size under different rolling temperatures in $\beta$-phase region are illustrated. It can be observed that at the higher temperatures of $1050^{\circ} \mathrm{C}$ and $1100^{\circ} \mathrm{C}$, the average grain size increases with the increase of rolling temperature. This is mainly because the higher temperatures provide enough driving force and lead to a substantial amount of nucleation, fast grain growth. The agreement of average grain size between experimental and simulated results is reasonably good.

\subsubsection{Effect of the roller rotating speeds}

Figure 17 show the metallographic images with different roller rotating speeds under the process conditions of the area reduction of $50 \%$ and rolling temperature of $950^{\circ} \mathrm{C}$. When the process conditions are kept unchanged, the microstructure with primary a and equiaxed a-phase can be observed as the roller rotating speed of $2 \mathrm{r} \cdot \mathrm{min}^{-1}$ is employed, as shown in Fig. 17a.As the roller rotating speed increased from 2 to $5 \mathrm{r} \cdot \mathrm{min}^{-1}$, the content and form of primary a have a little change. However, the grain content and grain size of platelet a phase increased obviously, as shown in Fig. 17b. When the roll speed increased from $5 \mathrm{r} \cdot \mathrm{min}^{-1}$ to $8 \mathrm{r} \cdot \mathrm{min}^{-1}$, the long-strip a primary phase and many smaller a primary phases appeared but the grain content of platelet aand equiaxed a phase decreased drastically, as shown in Fig. 17c. This is mainly because when the roller rotating speeds is slow, there is enough time for the grain to grow. On the contrary, when the roller rotating speeds is too fast, the time for grain growing is insufficient and will result in incomplete recrystallization of grains. In addition, with the increase of roller rotating speeds, the temperature rise (plastic heat effect) in Ti-6Al-4V alloy shaft is remarkable and will result in a decrease in the content of primary a phase.

In a word, the evolution in microstructure of Ti-6Al-4V alloy shaft versus roller rotating speed during CWR is complicated. After having several trials by error, the bimodal microstructure with $20 \%$ primary a phase can be achieved as the roller rotating speed of $5 \mathrm{r} \cdot \mathrm{min}^{-1}$ is employed, which have a positive impact on the microstructure and thus higher the performance of final products.

\subsubsection{Effect of the area reduction}

Figure 18 show the metallographic images with different area reduction rate under processing conditions of roller rotating speeds of $5 \mathrm{r} \cdot \mathrm{min}^{-1}$ and rolling temperature of $950{ }^{\circ} \mathrm{C}$. As the area reduction rate is $30 \%$, both primary $a$ and equiaxed a-phase can be observed in Fig. 18a, which is similar to Fig. 17a. As the area reduction rate increased from $30-50 \%$, the grain morphology and content of the primary a-phase did not change significantly but the grain size of the primary a phase gradually decreased and the distribution of platelet a became more uniform, as shown in Fig. 18b. When the area reduction rate continues to increase from $50-70 \%$, the microstructure is mainly composed of long-strip $a$ and equiaxed $a$, and the average grain size further decreases, as shown in Fig. 18c.

This is because the higher dislocation density and the stored energy due to the larger area reduction rate would be added so as to provide more driving force to promote the occurrence and completion of dynamic recrystallization, which can reduce the grain size. However, it also should be noted that 
excessive cross-sectional area reduction rate will make the primary a become abnormally slender and deteriorate the microstructure., The optimized area reduction rate of $50 \%$ around was chosen in this study with consideration of microstructure of Ti-6Al-4V alloy.

\section{Application}

To fabricate shaft preforms made of a TC4 alloy that has excellent mechanical properties is an innovative but challenge task. In the paper, $\mathrm{Ti}-6 \mathrm{Al}-4 \mathrm{~V}$ alloy shaft was manufactured successfully by Cross Wedge Rolling. However, it is essential step to measure tensile strength of Ti-6Al-4V alloy shaft formed by CWR.

The experiments for tensile test are designed according to national standard and the sample is prepared by wire cutting. The thickness is $1 \mathrm{~mm}$, the experimental equipment used in the tensile test is the universal material testing machine (type: Instron5966, made in China), and its sample diagram and tensile test process are shown in Fig. 19. In the experiment, the fracture of all tensile specimens occurred in the central part. The experimental results of tensile strength for the original material and the rolled formed shaft are tabulated in Table 5. The average tensile strength of the original material is $902.55 \mathrm{MPa}$, and the average tensile strength of the rolled shaft parts after cross-wedge rolling is $1070.23 \mathrm{MPa}$. It is found that the increase rate of tensile strength reached $18.57 \%$ for rolled shaft part, as expected.

To facilitate observation and understanding of the fracture form of the tensile specimen, so as to further understand the mechanical properties of the rolled shaft, scanning electron microscope (type:SU500, made in Japan) was used to observe the surface morphology of the tensile fracture specimen. The fracture surface morphology of the tensile specimen is shown in Fig. 20. It is observed that the fracture is a type of ductile fracture which is mainly composed of dimples of different diameters and inclusions. In general, for a plastic material with the more dimples, the deeper and the larger the dimples will provide the better the plastic performance. It can be analyzed from the Fig. $20 \mathrm{~d}$, e and $\mathrm{f}$ are obviously dimples more and deeper than Fig. 20a, b and c, indicating that the plastic properties of rolled pieces are significantly improved after rolling. 
Table 5

Comparison of tensile strength

\begin{tabular}{|llll|}
\hline & Serial no. & the tensile strength(MPa) & Average tensile strength(MPa) \\
\hline Billet & 1 & 898.96 & 902.55 \\
& 2 & 903.13 & \\
& 3 & 905.56 & 1070.23 \\
The rolled shaft & 4 & 1058.24 & \\
& 5 & 1071.89 & $18.57 \%$ \\
\hline
\end{tabular}

\section{Conclusions}

In this paper, a study is carried out both numerically and experimentally on the microstructure evolution of Ti-6Al-4V alloy in Cross-Wedge Rolling process. The conclusions can be made as follows:

1. The microstructure evolution of A Ti-6Al-4V alloy during CWR can be predicted and measured both numerically and experimentally. The difference of the average grain size between the simulation and experiment is ranged from $5.77 \%$ to $18.56 \%$, which is reasonably good.

2. The influence law of different CWR conditions on the microstructure evolution in the $\alpha+\beta$ two-phase region was obtained both numerically and experimentally. The dynamic recrystallization volume fraction increases with the increase of rolling temperature and area reduction rates, but decreases with the increase of roller rotating speeds. The temperature change has the greatest effect on the content of primary $a$, and the content of primary a decreases with the increase of rolling temperature. The grain size of primary a decreases with the increase of rolling temperature, roller rotating speeds and area reduction rates.

3. With the increase of rolling temperature, the average grain size increases. With the increase of roller rotating speeds and area reduction rates, the average grain size decreases. Both numerical simulation and experimental results show that the products formed by the CWR process possess a fine grain and bi-model microstructure. Through CWR, the tensile strength of Ti-6Al-4V alloy shaft preform increased compared with the billets and the plasticity enhanced significantly. The results will provide a fundamental understanding for further improving the Ti-6Al-4V alloy material utilization of CWR and the comprehensive mechanical properties of shaft preform.

\section{Declarations}

\section{Acknowledgements}


We gratefully acknowledge that the project was supported by National Natural Science Foundation of P.R. China (Grant No. 51975301) and by Ningbo Municipal Science and Technology Innovation Major Project (Grant No. 2020Z110). The work was also sponsored by K. C. Wong Magna Fund in Ningbo University.

\section{References}

1. Ji SD, Li ZW, Wang Y, Ma L (2017) Joint formation and mechanical properties of back heating assisted friction stir welded Ti-6Al-4V alloy. Materials Design 113:37-46

2. Elias CN, Lima JHC, Valiev R, Meyers MA (2008) Biomedical applications of titanium and its alloys. Biological Materials Science 60:46-49

3. Srinivasu GS, Raja NR (2012) Finite element modeling of stress strain curve and micro stress and micro strain distributions of titanium alloy-a review. Journal of Minerals Materials Characterization Engineering 11:953-960

4. Fan XG, Yang H, Gao PF, Deformation behavior and microstructure evolution in multistage hot working of TA15 titanium alloy: on the role of recrystallization, Journal of Materials Science, 46 (2011) 6.18-6.28

5. Chamos AN, Labeas GN, Setsika D (2013) Tensile behavior and formability evaluation of titanium-40 material based on the forming limit diagram approach. Journal of Materials Engineering Performance 22:2253-2260

6. Ezugwu EO, Wang ZM, Titanium alloys and their machinability- a review, Journal of Materials Processing Technology, 68 (1997) 262-274. [5] Guo P, Zhao YQ, Zeng WD, Hong Q, The effect of microstructure on the mechanical properties of TC4-DT titanium alloys, Materials Science \& Engineering A, 563 (2013) 106-111

7. Li JL, Wang BY, Ji HC, Huang X, Tang XF, Ma WP (2017) Effects of the cross-wedge rolling parameters on the formability of Ti-6Al-4V alloy. International Journal Advanced Manufacture Technology 92:2217-2229

8. Huo YM, Bai Q, Wang BY, Lin JG, Zhou J (2015) A new application of unified constitutive equations for cross wedge rolling of a high-speed railway axle steel. J Mater Process Technol 223:274-283

9. Ji HC, Liu JP, Wang BY, Zhang ZR, Zhang T, Hu ZH (2015) Numerical analysis and experiment on cross wedge rolling and forging for engine valves. J Mater Process Technol 221:233-242

10. Fang G, Lei LP, Zeng P (2002) Three-dimensional rigid-plastic finite element simulation for the tworoll cross-wedge rolling process. J Mater Process Tech 129(1-3):245-249. doi:10.1016/S09240136(02)00610-6

11. Wang MH, Xiang D, Xiao C, Zhou J, Jia Z (2012) Influence of cooling condition of tools on central deformation of workpiece and tool wear in cross wedge rolling. Int J Adv Manuf Technol 59(58):473-482. doi:10.1007/s00170-011-3537-6

12. Zhou J, Yu YY, Zeng Q (2014) Analysis and experimental studies of internal voids in multi-wedge cross wedge rolling stepped shaft. Int J Adv Manuf Technol 72(9-12):1559-1566. 
doi:10.1007/s00170-014-5768-9

13. Pater $Z$ (2000) Theoretical and experimental analysis of cross wedge rolling process. Int $J$ Mach Tools Manuf 40(1):49-63. doi:10.1016/S0890-6955(99)00047-4

14. Pater Z, Gontarz A, Weroński W (2006) Cross-wedge rolling by means of one flat wedge and two shaped rolls. J Mater Process Tech 177(1-3):550-554. doi:10.1016/j.jmatprotec.2006.03.232

15. Pater Z (2010) Development of cross-wedge rolling theory and technology. Steel Res Int 81(9):25-32

16. Li Q, Lovell MR, Slaughter W, Tagavi K (2002) Investigation of the morphology of internal defects in cross wedge rolling. J Mater Process Tech 125(02):248-257. doi:10.1016/S0924-0136(02)00303-5

17. Li Q, Lovell MR (2004) The establishment of a failure criterion in cross wedge rolling. Int J Adv Manuf Technol 24(24):180-189. doi:10.1007/s00170-003-1607-0

18. Urankar S, Lovell MR, Morrow C, Li Q, Kawada K (2006) Establishment of failure conditions for the cross-wedge rolling of hollow shafts. J Mater Process Tech 177(1-3):545-549. doi:10.1016/j.jmatprotec.2006.04.052

19. Li Q, Lovell M (2008) Cross wedge rolling failure mechanisms and industrial application. Int J Adv Manuf Technol 37(3-4):265-278. doi:10.1007/s00170-007-0979-y

20. Lee HW, Lee GA, Yoon DJ, Choi S, Na KH, Hwang MY (2008) Optimization of design parameters using a response surface method in a cold cross-wedge rolling. J Mater Process Tech 201(s 1-3):112117. doi:10.1016/j.jmatprotec.2007.11.287

21. Li JL, Wang BY, Ji HC, Huang X, Tang XF, Ma WP (2017) Effects of the cross-wedge rolling parameters on the formability of Ti-6Al-4V alloy. International Journal Advanced Manufacture Technology 92:2217-2229

22. Li JL, Wang BY, Ji HC, Zhou J, Fu XB, Huang X (2018) Numerical and experimental investigation on the cross-wedge rolling of powder sintering TC4 alloy. International Journal Advanced Manufacture Technology 94:2149-2162

23. Pater Z, Tomczak J (2012) Experimental tests for cross wedge rolling of forgings made from nonferrous metal alloys. Achieves of Metallurgy Materials 57(04):919-928

24. Pater Z, Bulzak T, Tomczak J (2016) Cross-Wedge Rolling of Driving Shaft from Titanium Alloy Ti6Al4V. Key Eng Mater 687:125-132

25. Arkadiusz T, Janusz T, Tomasz B (2016) Comparative analysis of forging rolling and cross-wedge rolling of forgings from titanium alloy Ti6Al4V. Key Eng Mater 687:141-148

26. Li J, Wang B, Qin Y, Fang S, Huang X, Chen $P$ (2019) Investigating the effects of process parameters on the cross wedge rolling of TC6 alloy based on temperature and strain rate sensitivities. The International Journal of Advanced Manufacturing Technology 103(5-8):2563-2577

27. Ding R, Guo ZX (2004) Microstructural evolution of a Ti-6Al-4V alloy during $\beta$-phase processing: experimental and simulative investigations. Materials Science Engineering: A 365(1-2):172-179

28. Li J, Wang B, Fang S, Chen $P$ (2020) Investigation of the microstructure evolution and mechanical properties of a TC6 alloy blade preform produced by cross wedge rolling. Archives of Civil and 
Mechanical Engineering 20(3)

29. Wahed MA, Gupta AK, Sharma V et al., Material characterization, constitutive modelling, and processing map for superplastic deformation region in Ti-6Al-4V alloy, Int. J. Adv. Manuf. Technol. (3) (2019)

30. Alabort E, Kontis P, Barba D et al (2016) On the mechanisms of super plasticity in Ti-6Al-4V. Acta Mater 105:449-463

31. Alabort E, Putman D, Reed RC (2015) Super plasticity in Ti-6Al-4V: Characterisation, modelling and applications. Acta Mater 95:428-442

32. Rhaipu S (1998) The effect of microstructural gradients on superplastic forming of Ti-6Al-4V. J Mater Process Technol 80:90-95

33. Li Shenke. Microstructure simulation of TC4 titanium alloy based on DEFORM-3D [D]. Nanchang Aeronautical University,2017

34. Li J, Wang B, Ji H et al (2017) Effects of the cross-wedge rolling parameters on the formability of Ti6Al-4V alloy. Int J Adv Manuf Technol 92:2217-2229. doi.org/10.1007/s00170-017-0263-8

35. Whittenberger JD (1986) The influence of grain size and composition on plastic flow in Fe-A1 between 1100 and $1400 \mathrm{~K}[\mathrm{~J}]$. Materials Science Engineering 77:103-106

36. Jyoti S, Jha A, Tewari S, Mishra et al (2017) Constitutive relations for Ti-6Al-4V hot working[J]. Procedia Eng 173:755-762

\section{Tables}

Due to technical limitations, table 2 is only available as a download in the Supplemental Files section.

\section{Figures}




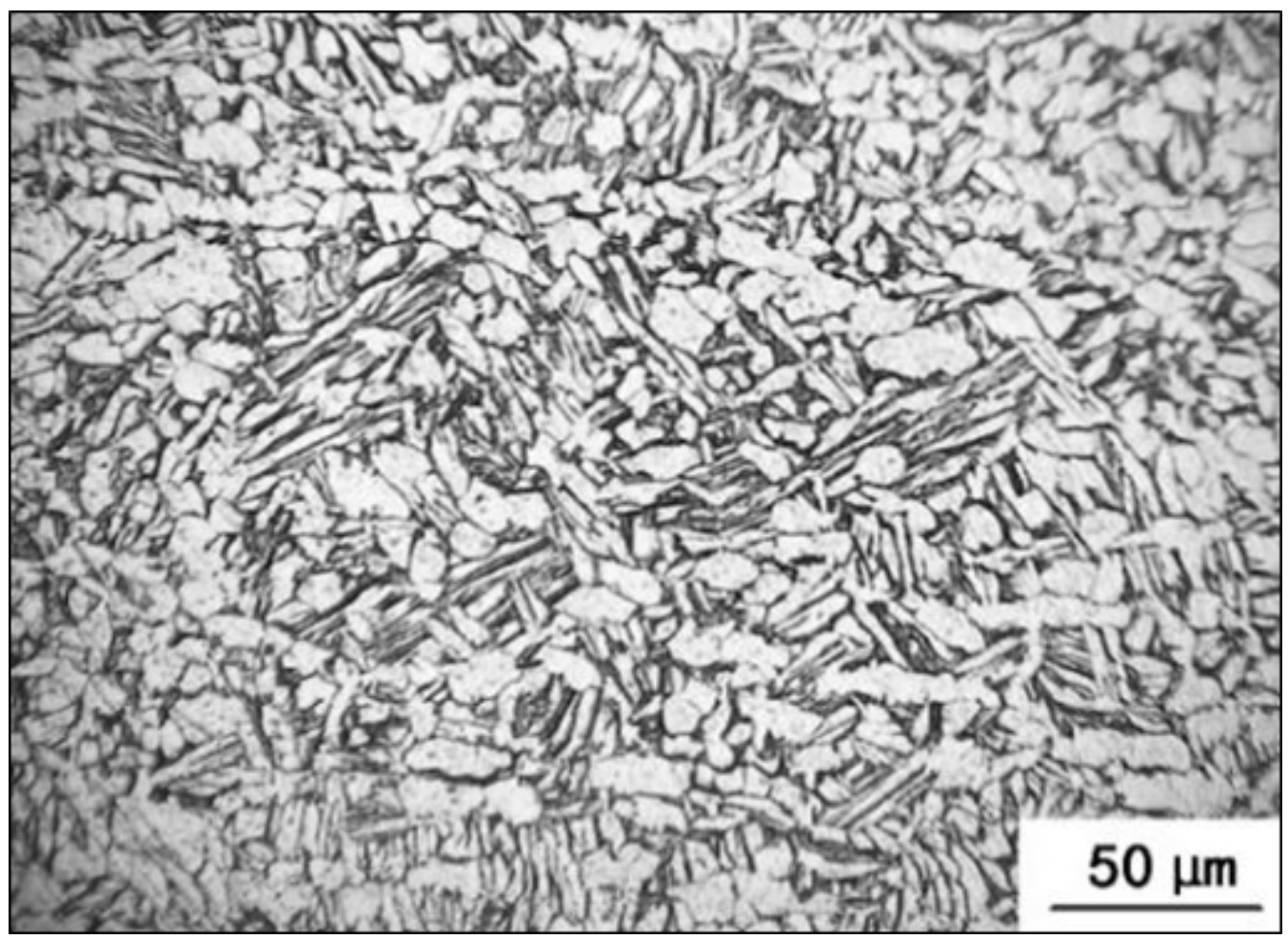

Figure 1

The initial microstructure structure of $\mathrm{Ti}-6 \mathrm{Al}-4 \mathrm{~V}$ alloy

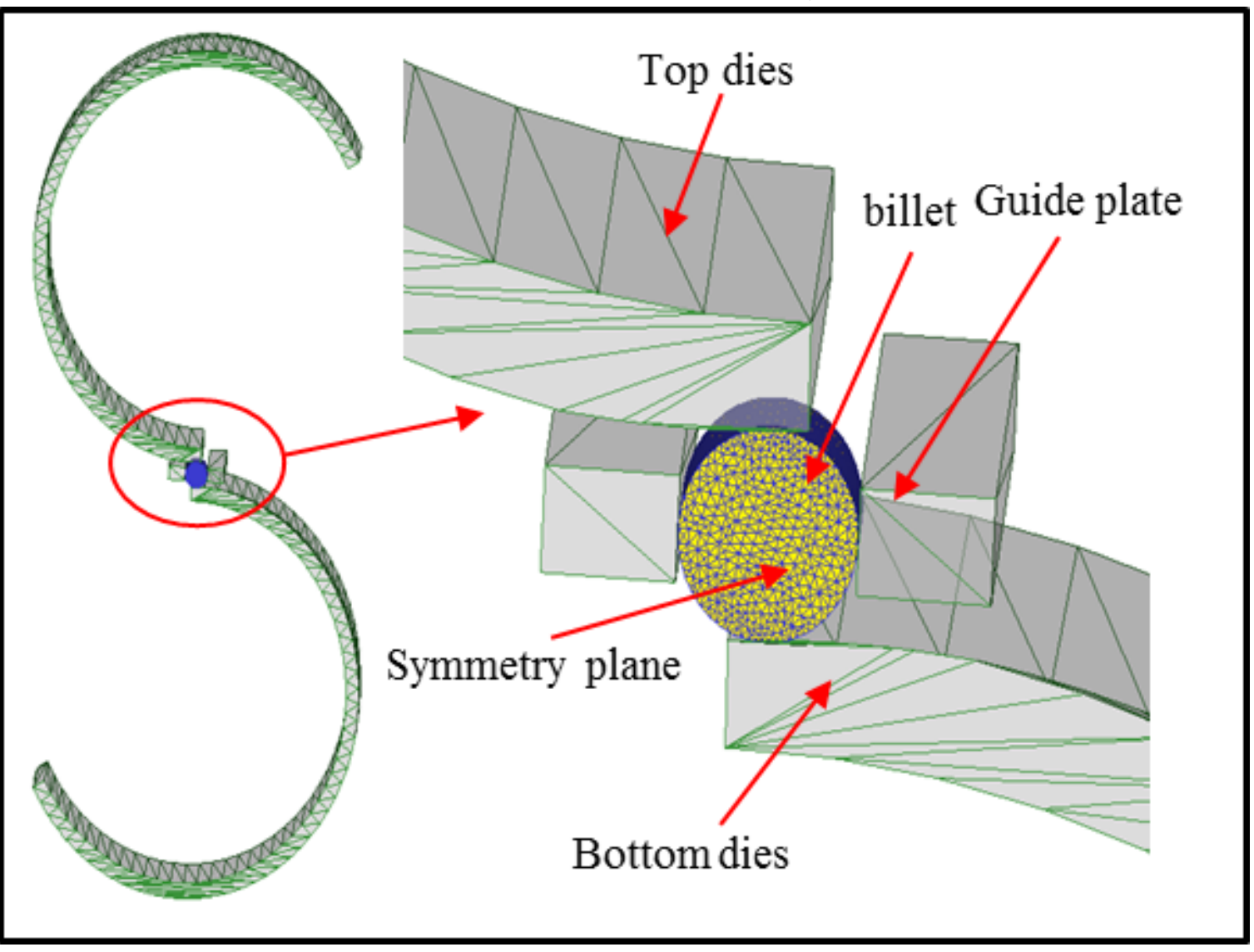

Figure 2 
Finite element model of cross wedge rolling
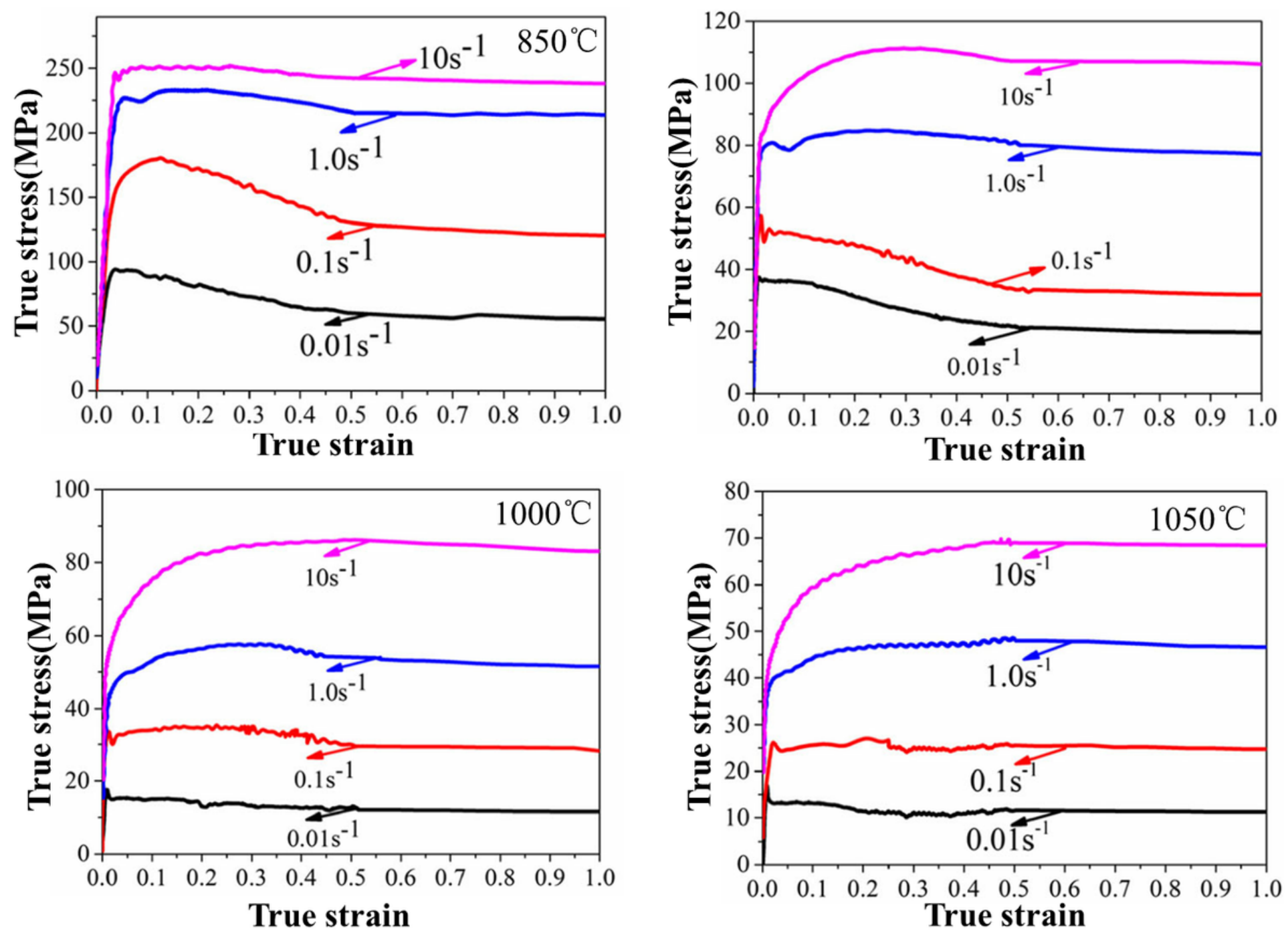

Figure 3

The typical true stress-strain curve of Ti-6Al-4V at different temperature

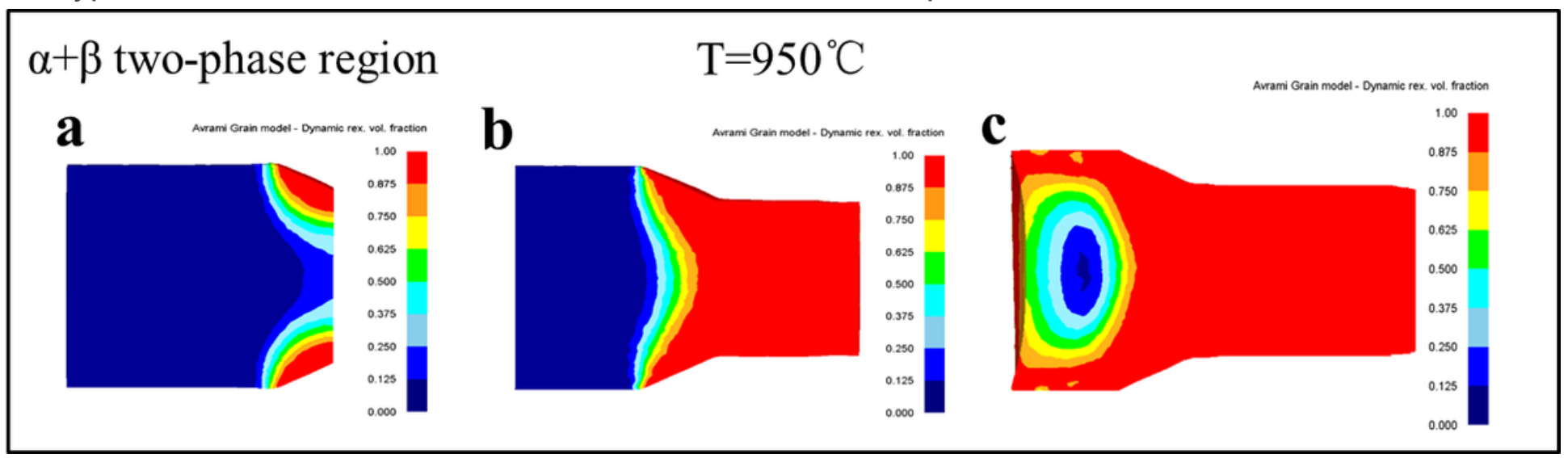

Figure 4 
Dynamic recrystallization volume fraction in $a+\beta$ two-phase region at different stage $₫ a$ knifing zone, $b$ stretching zone, c sizing zone

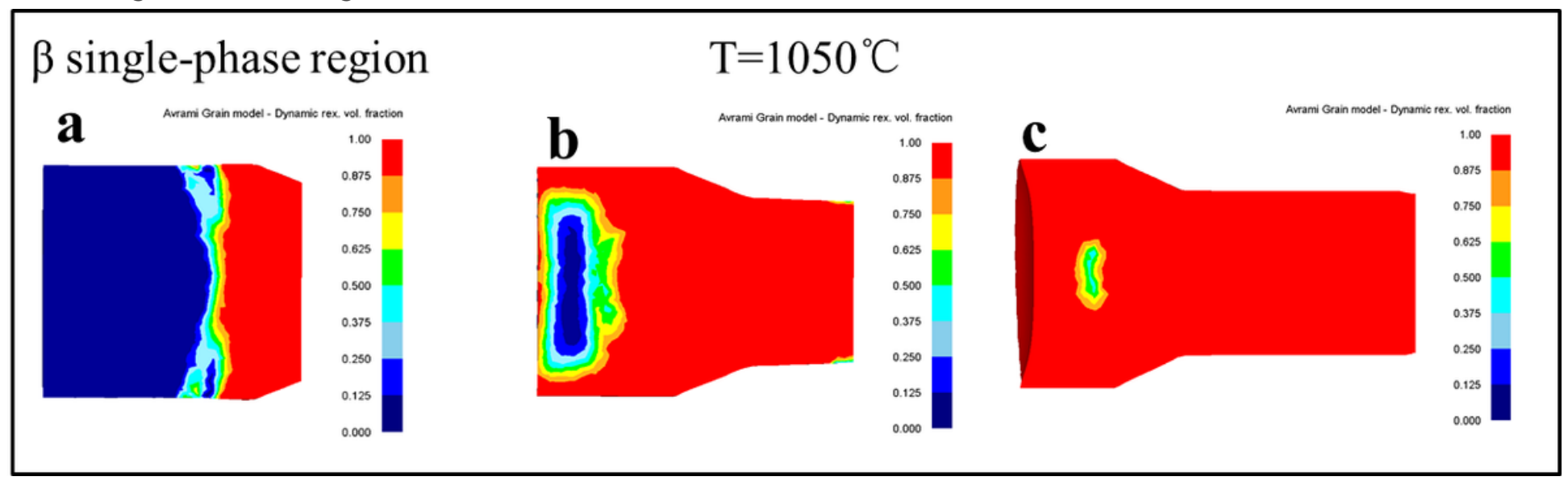

Figure 5

Dynamic recrystallization volume fraction in $\beta$ single-phase region at different stage $\llbracket a$ knifing zone, $b$ stretching zone, c sizing zone

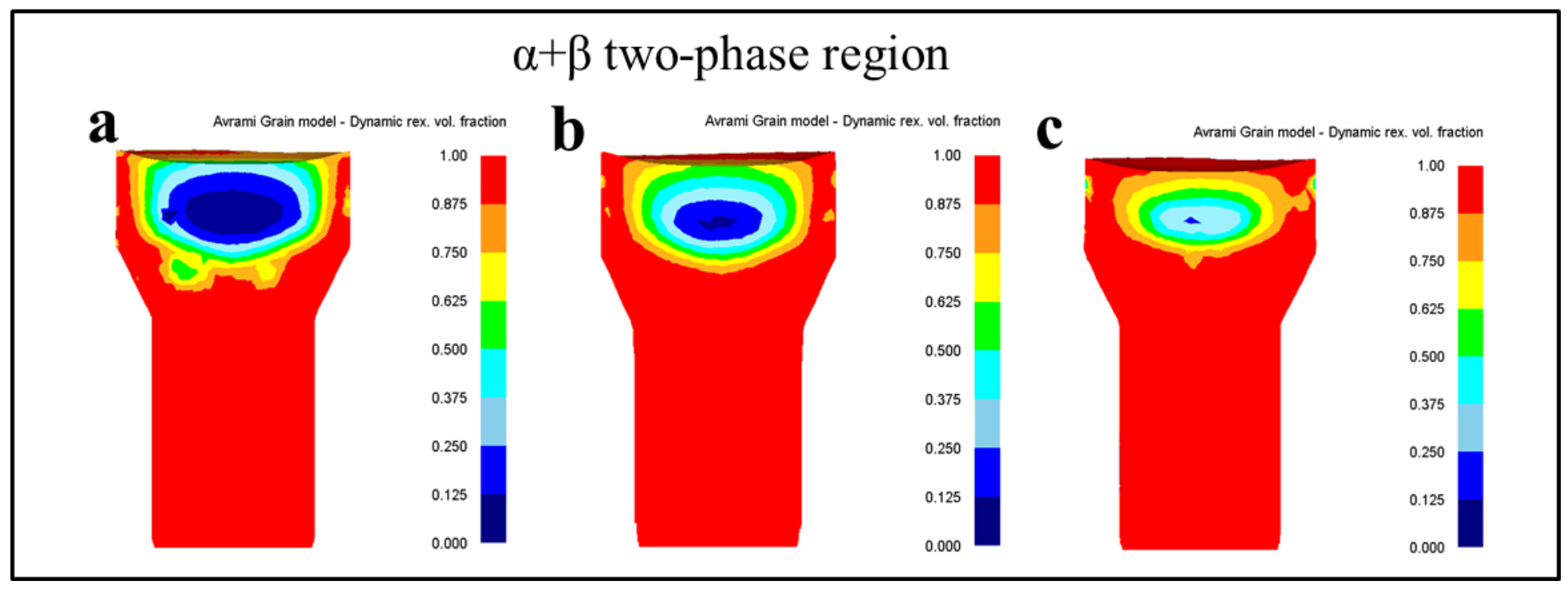

\section{Figure 6}

The dynamic recrystallization volume fraction of Ti-6Al-4V at different temperatures during $\alpha+\beta$ twophase region: a 850, b $900, \mathrm{c} 950{ }^{\circ} \mathrm{C}$ 


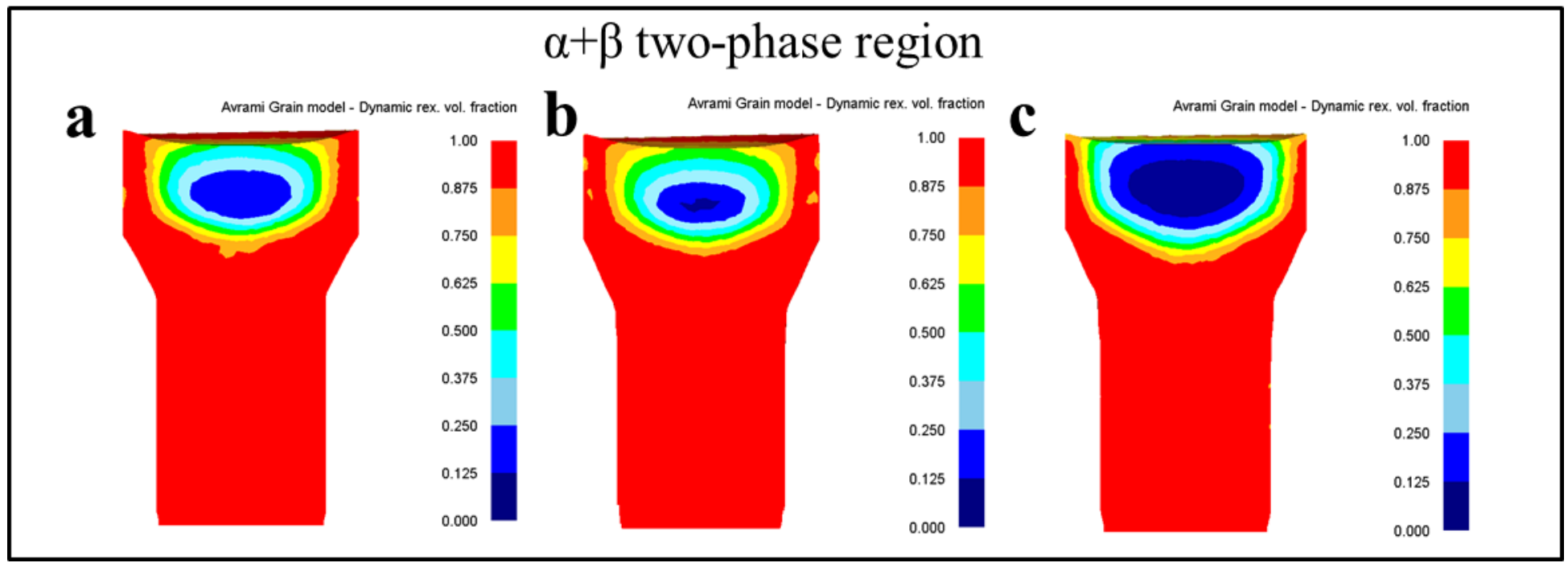

Figure 8

The dynamic recrystallization volume fraction of Ti-6Al-4V at different roller rotating speeds during $\alpha+\beta$ two-phase region: a 2, b 5,c 8r·min-1

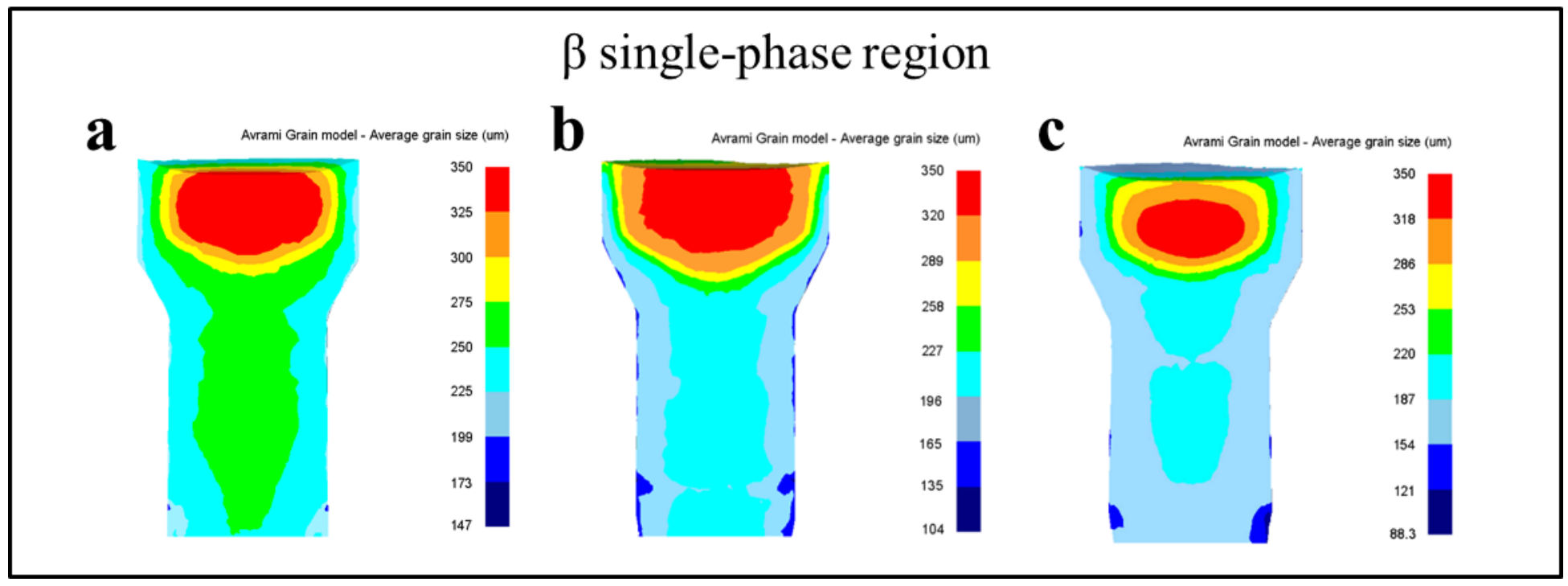

Figure 9

The average grain size of Ti-6Al-4V at different roller rotating speeds during $\beta$ single-phase region: $a 2, b$ $5, \mathrm{c} 8 \mathrm{r} \cdot \mathrm{min}-1$ 


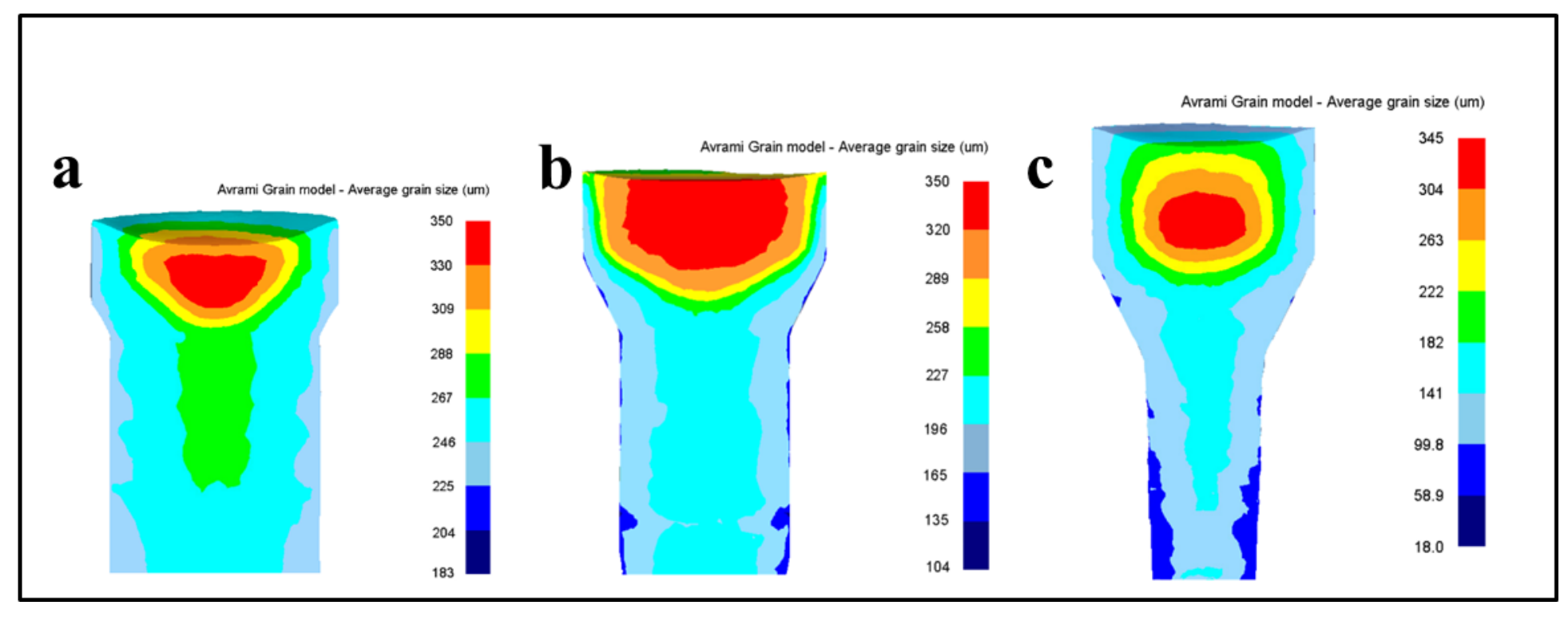

Figure 11

The average grain size of Ti-6Al-4V under different area reduction rates during $\beta$ single-phase region: a 30 , b 50, c $70 \%$

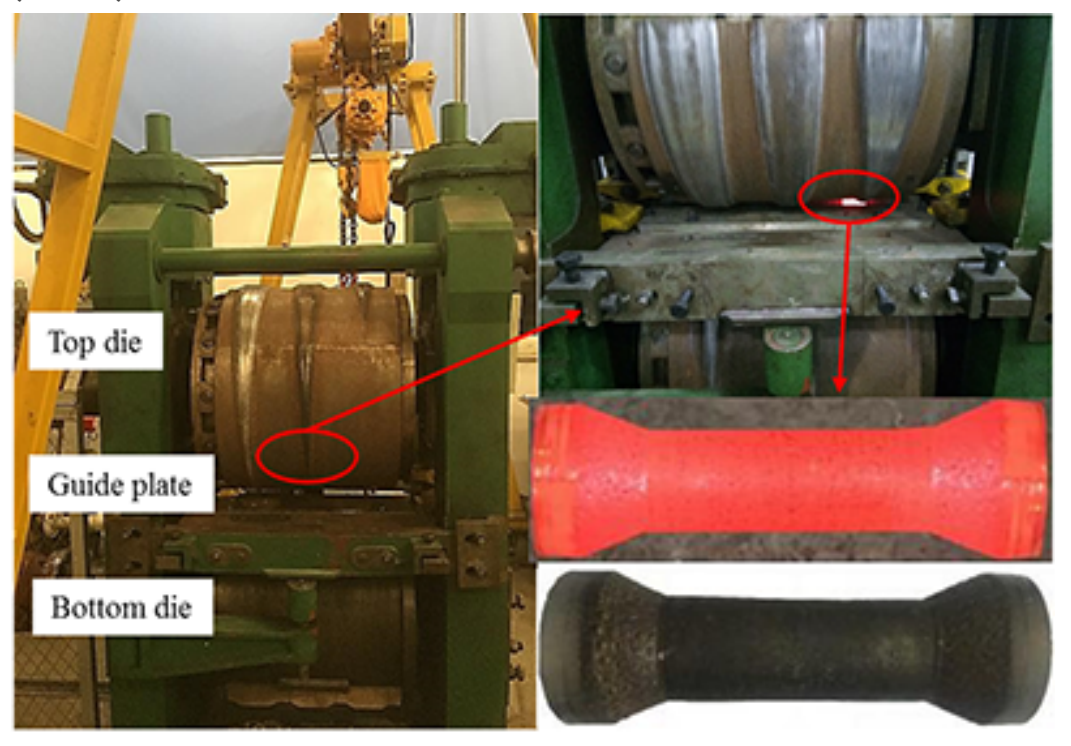

Figure 12

The $\mathrm{H} 630 \mathrm{CWR}$ mill and rolling process 

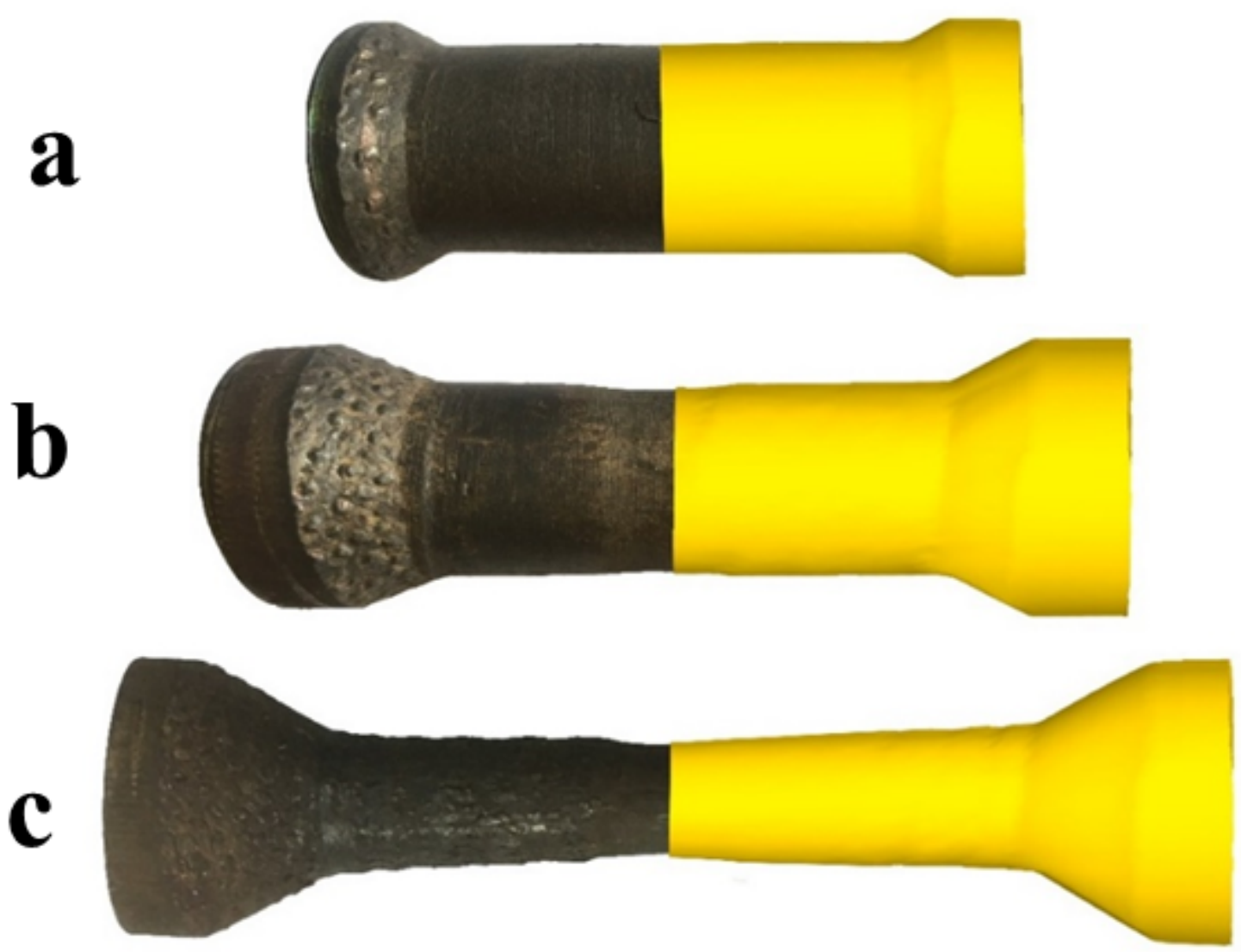

Figure 13

Comparison between the results through simulation and experiment under different area reduction rates :a 30, b 50, c $70 \%$

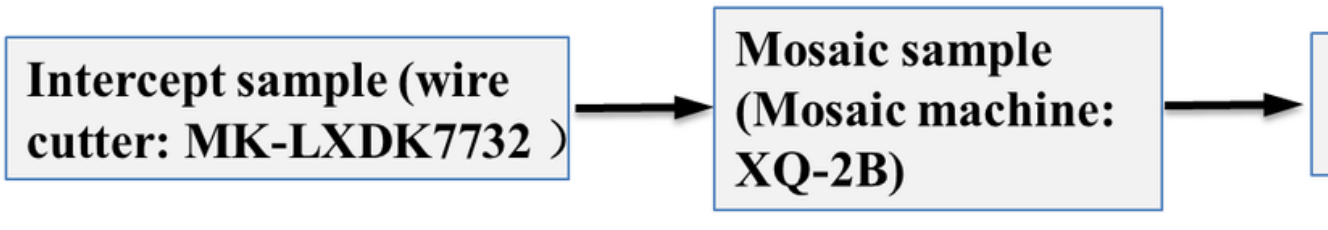

Metallographic observation (HiROXKH-8700)

\begin{tabular}{l} 
Sample corrosion \\
(saturated picric \\
acid solution) \\
\hline
\end{tabular}

Abrasive sample (multispecification sandpaper)

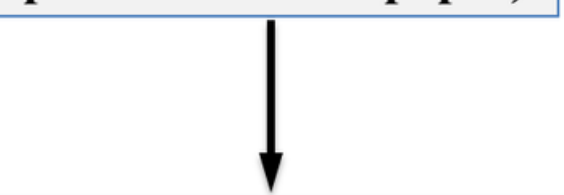

Sample polishing (metallographic polishing machine:PG-2B)

Figure 14

The flowchart of microstructure measurement 


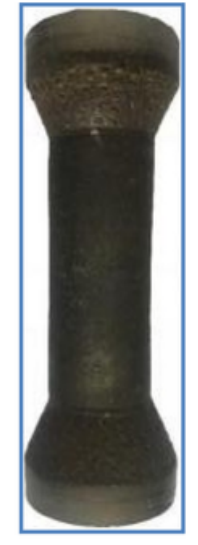

The finished TC4 shaft preform
Cut into two halves along the axis symmetrically

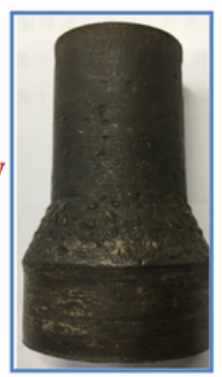

$1 / 2$ of the finished TC4 shaft preform

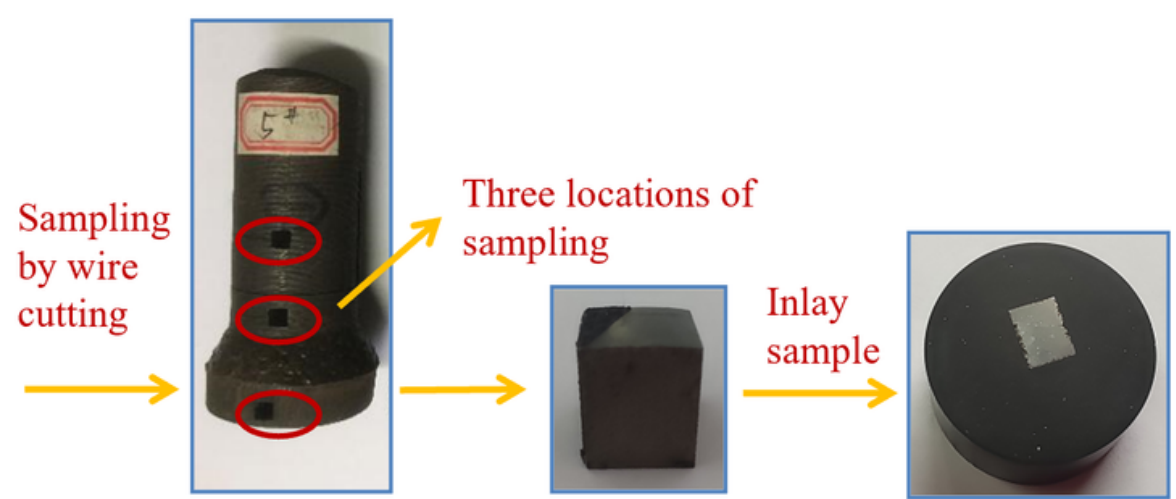

shaft preform after wire cutting
$(5 \times 5 \times 5 \mathrm{~mm})$ metallographic specimens

\section{Figure 15}

The metallographic sampling diagram of the finished TC4 shaft preform by CWR 

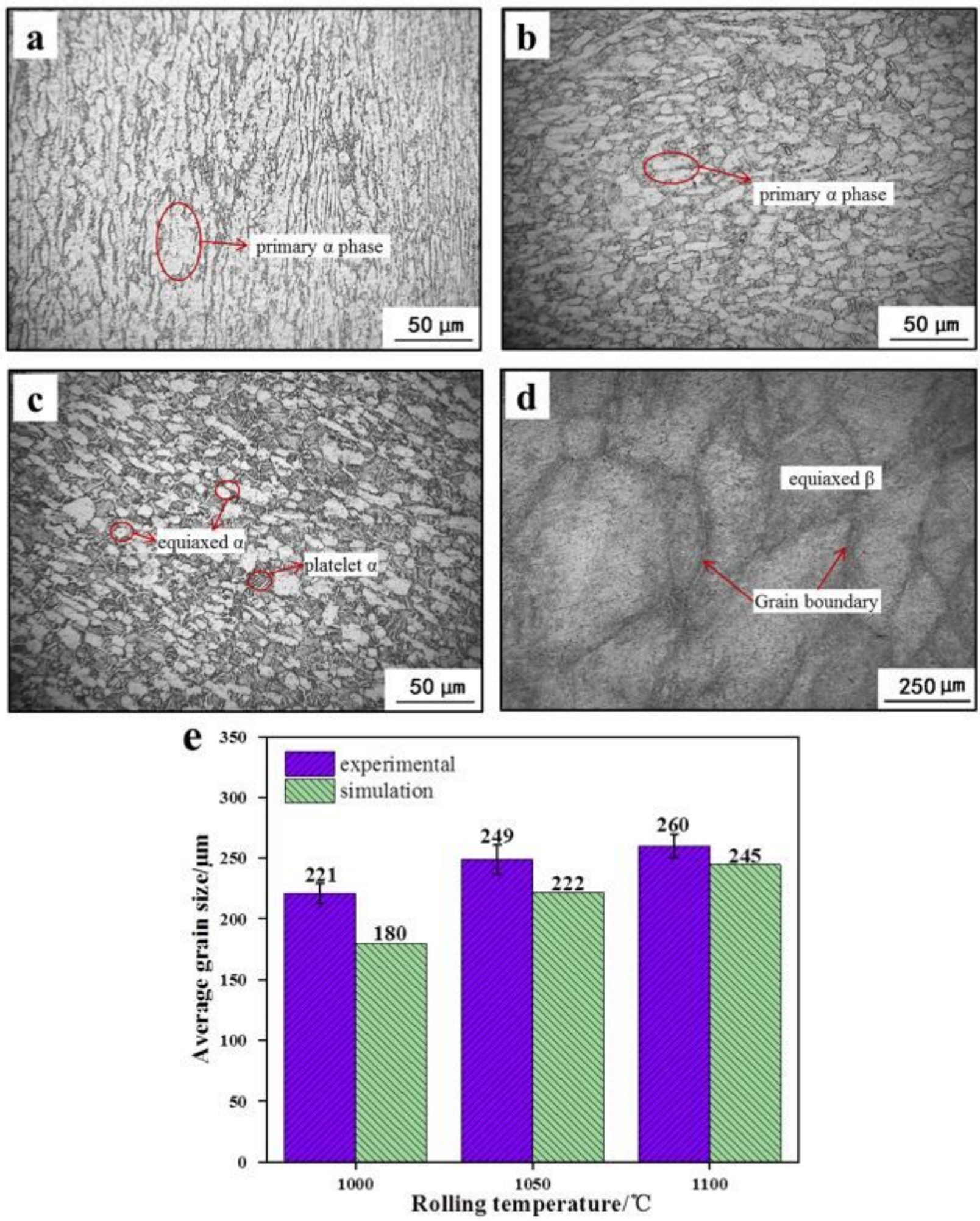

Figure 16

Effect of rolling temperature on microstructure for an area reduction rate of $50 \%$ and roller rotating speeds of $5 \mathrm{r} \cdot \mathrm{min}-1$ : a $850{ }^{\circ} \mathrm{C}, \mathrm{b} 900^{\circ} \mathrm{C}, \mathrm{c} 950, \mathrm{~d} 1000^{\circ} \mathrm{C}$,e Average grain size in $\beta$ single-phase region under different rolling temperature 

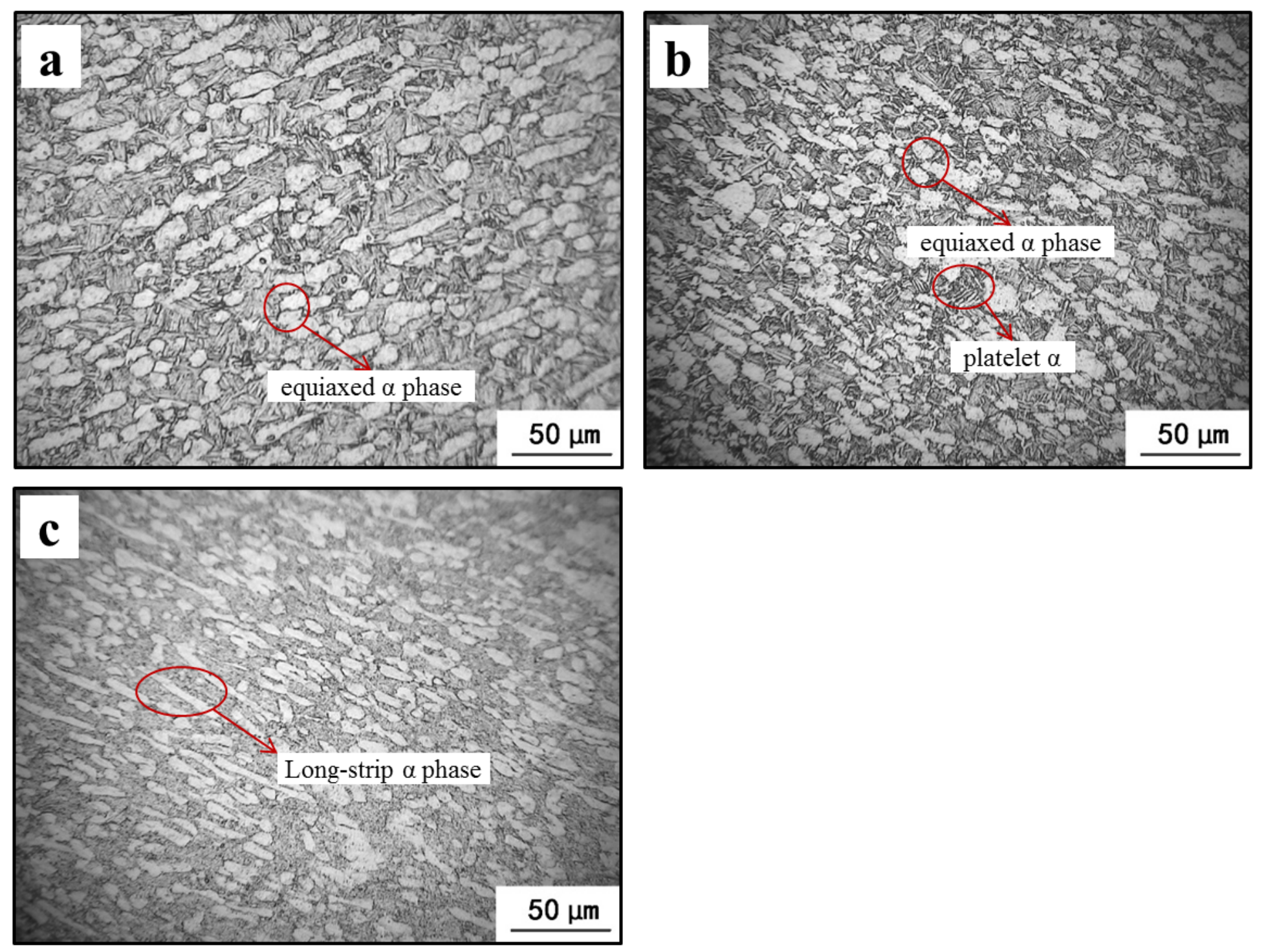

Figure 18

Effect of area reduction rates on microstructure of the rolled Ti-6Al-4V alloy shaft for the rolling

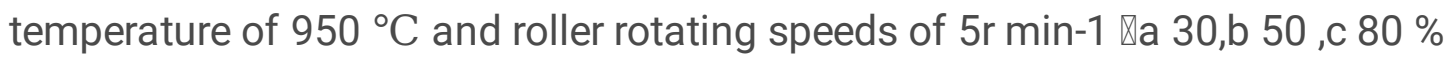




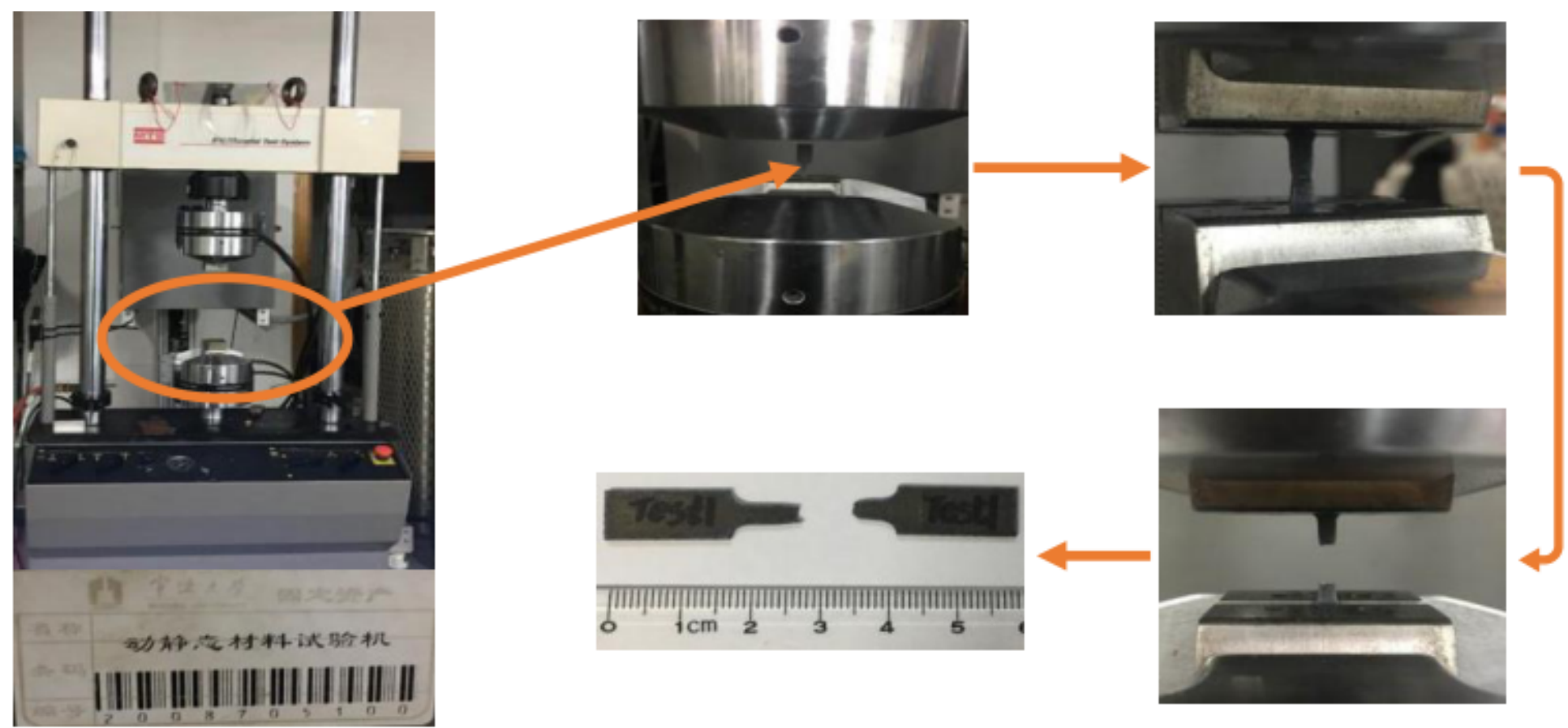

Figure 19

The flowchart of tensile test 

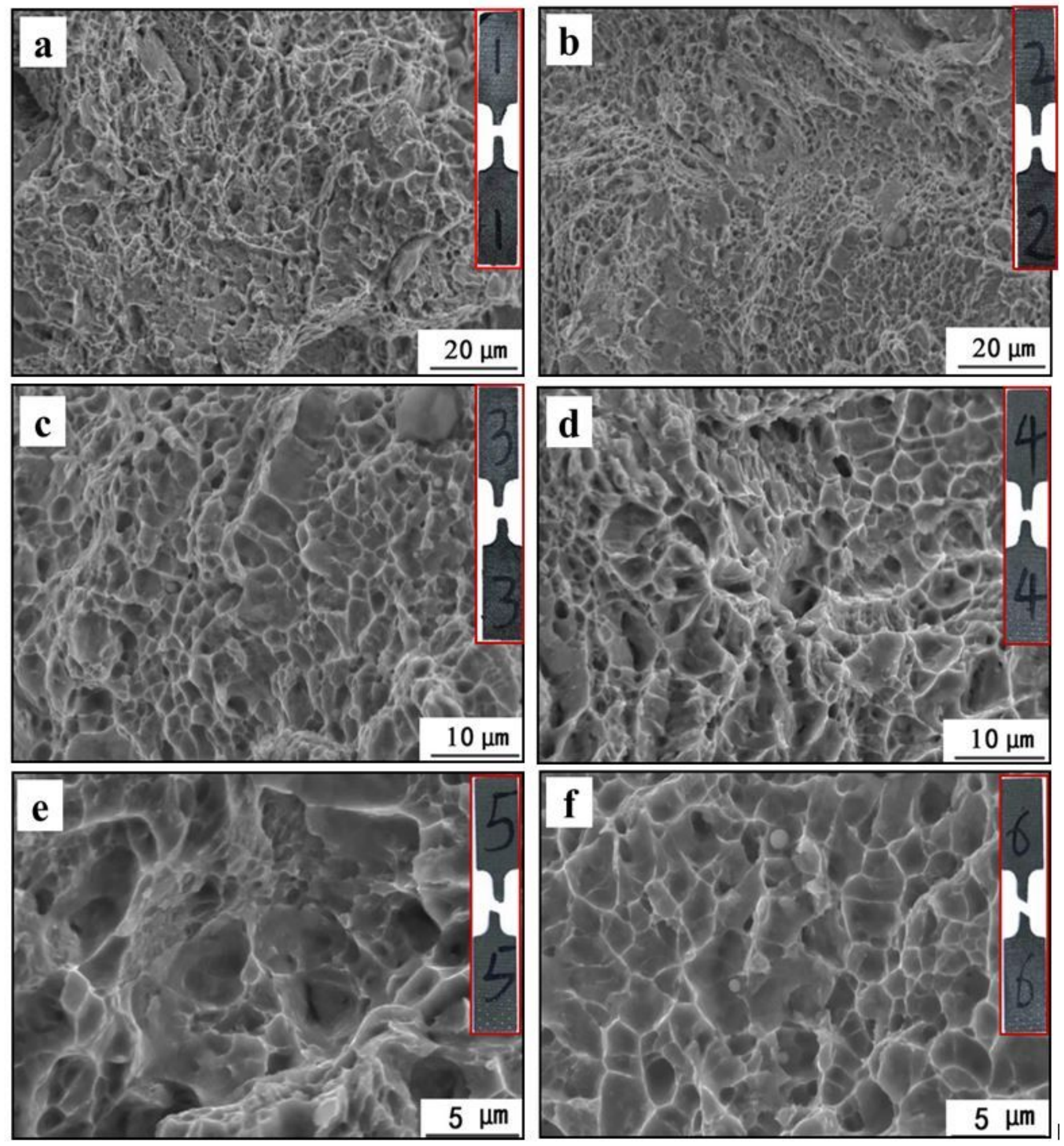

Figure 20

Surface morphology of tensile fracture

\section{Supplementary Files}

This is a list of supplementary files associated with this preprint. Click to download. 
- Table2.jpg

Page 27/27 